\title{
Land Use and Land Cover Change Detection in the Bhavani Basin of India through Remote Sensing Approach
}

\section{DOI:10.36909/jer.ACMM.16339}

\author{
Manikandan. $\mathrm{K}^{1}$ and SathyanathanRangarajan ${ }^{2 *}$ \\ ${ }^{1}$ Research Scholar and ${ }^{2}$ Associate Professor \\ Department of Civil Engineering, College of Engineering and Technology, \\ SRM Institute of Science and Technology, \\ SRM Nagar, Kattankulathur, 603 203, Kanchipuram, Chennai, TN, India. \\ *Corresponding author: sathyanr5@srmist.edu.in
}

\begin{abstract}
Using remote sensing data to detect changes in land use and land cover (LULC) is a valuable source of information for various decision support systems. Land use and land cover identification data was used to analyse land conservation, sustainable development, and water resource management. This research aims to determine how the Bhavani basin land use and land cover have changed over the period of time. Land cover changes were detected using Landsat Thematic Mapper (TM) 30 m resolution images in the GIS environment and with image processing techniques for the four years 1999, 2007, 2014, and 2020. The differences in the landuse and land cover classes are described using ERDAS imagine version 2015 and ARC GIS software. The four land cover classes viz. water body, built-up land, barren land, and vegetation were used to classify the region. The accuracy evaluation was assessed separately using the kappa coefficient after carefully examining the image pre-processing and classification. The overall accuracy in the basin was found to be $83.23 \%, 86.45 \%, 85.83 \%$, and $88.75 \%$ with a kappa coefficient of $0.79,0.81,0.87,0.85$ for the years 1999, 2007, 2014, and 2020 respectively. The Bhavani basin is mostly covered by barren and vegetation. According to the findings, the basin's built-up area has risen by 1.5 percentage to 3.5 percentage in the last 20 years. The increase in the vegetation area and reduction in the barren area may lead to low soil erosion.
\end{abstract}

Keywords: Bhavani basin, LULC, Landsat TM, Remote sensing, Supervised Classification

\section{INTRODUCTION}

The terms "land cover" and "land use" are sometimes used interchangeably; they have somewhat different definitions (J. S. Alawamy et al., 2020). Whether it is trees, urban infrastructure, water, bare soil, or anything else, the earth's surface layer is a land cover. Land cover is essential for global monitoring studies, resource management, and reservoir planning operations (M. H. Saputra et al., 2019). Land cover identification establishes a baseline for change detection in monitoring activities and provides ground cover data for baseline thematic maps (U. Imran Basha et al., 2018). Land use refers to how the land is used, such as for recreation, wildlife habitat, or agriculture (M. H. Saputra et al., 2019). Land use applications include baseline mapping and subsequent tracking because timely information is required to know the current quantity of land in what type of service and to distinguish landuse changes from year to year (S. Twisa et al., 2019). 
The change in LULC of a region, significantly the increase in built-up areas, alters hydrological processes such as runoff pattern, peak flow characteristics, water quality, and so on, whether intentionally or inadvertently (B. Ebenezer et al., 2018). LULC studies are critical in producing and managing water supplies because they directly affect river basins' hydrological processes (E. D. Ashaolu et al., 2018). Changes in land use in a watershed may affect water quality and supply. Due to watershed development, land use patterns regularly shift, resulting in increased surface runoff, decreased groundwater recharge, and pollutant transfer (B. Ebenezer et al., 2018). An area's physical landform is defined by the number of trees, impervious surfaces, agricultural fields, wetlands, and open water that cover it. LULC shift identification helps to understand landscape dynamics over time with sustainable management (Das \& Sarkar, 2019). Land use/cover shift is a massive and increasing phenomenon fuelled primarily by natural and anthropogenic events, resulting in changes that affect natural ecosystems (Butt et al., 2015).

On the other hand, land use refers to how people use the land for development, conservation, or a combination of the two (Chowdhury et al., 2020). Remote sensing (RS) and geographic information systems (GIS) are reliable and effective for land and other natural resource management methods in land change inquisition. Scientists, environmentalists, agriculturalists, policymakers, and urban planners benefit from analysing and tracking LULC shifts (S. Das et al., 2019). LULC patterns and improvements have been detected and tracked using satellite-based technology advances, RS and GIS (Mzava et al., 2019). Landscape shift models help decipher the forces that form landscapes. One justification for modelling is to see what long-term effects extrapolating short-term landscape dynamics can have (Alam et al., 2021). Geo-analysis models for tracking LU/LC status and dynamic change have become one of the most rapid, accurate, and efficient methods available today, thanks to the development of more advanced RS and GIS technologies (Das \& Sarkar, 2019). RS and GIS are essential and reliable tools for evaluating LULC changes at different scales. Many image analyses and shift detection methods have been used (Twisa \& Buchroithner, 2019). Satellite RS and GIS are the most common methods for quantifying, monitoring, and detecting LU/LC patterns due to their precise geo-referencing techniques, a digital format suitable for computer processing, and repetitive data collection (Hassan et al., 2016). Better land use landcover management required changes in the temporal dimension. Thus, the monitoring of the land use land cover changes is needed to compete with the growing population and climate change effects (Elagouz et al., 2020). Overall, studying LU/LC change identification is beneficial to future generations for the current study's proper planning and management activities.

\section{Study Area}

Bhavani Sagar basin is located between latitude $10^{\circ} 56^{\prime \prime} 3^{\prime} \mathrm{N}$ to $11^{\circ} 46^{\prime \prime} 14^{\prime} \mathrm{N}$ and longitude $76^{\circ} 24^{\prime \prime} 41^{\prime} \mathrm{E}$ to $77^{\circ} 41^{\prime \prime} 11^{\prime} \mathrm{E}$. The drainage area of the Bhavani basin is $5537 \mathrm{~km}^{2}$. The coverage of basin area includes three states viz., Kerala (14\%), Karanataka (7\%) and Tamilnadu (87\%). Bhavani dam is constructed at the confluence of two rivers, Bhavani and Moyar. Water is diverted to the lower Bhavani project canal through the dam. The Bhavani basin is significant in terms of agriculture, with $2437 \mathrm{~km}^{2}$ of cultivated land. The basin is influenced by the monsoons from the southwest and northeast. The southwest monsoon 
brings more flows to the upper reaches, while the northeast monsoon brings more to the lower reaches. The river originates from the Billimala range of Nilgiris district at an altitude of $2643 \mathrm{~m}$ (Narayanamurthi, 2020). The watershed receives rainfall due to the influence of both the southwest and northeast monsoons. The maximum and minimum temperature ranges between $34^{\circ} \mathrm{C}$ and $19.2^{\circ} \mathrm{C}$ during the summer season and between $22^{\circ} \mathrm{C}$ and $5.1^{\circ} \mathrm{C}$ during the winter season, depending on the year's location and time (Narayanamurthi, 2020). The northeast monsoon, which runs from August to December, brings the most rain. Coimbatore had a mean daily relative humidity of $29 \%$ in March, and Ooty had a mean daily humidity of $91 \%$ in July. The Bhavani basin's average annual rainfall is $811.47 \mathrm{~mm}$, with computed annual rainfall ranging from $544.70 \mathrm{~mm}$ in Annur, Coimbatore district, to $2251.00 \mathrm{~mm}$ in Gudalore, Nilgiri district (River Basin \& Nadu, n.d.).
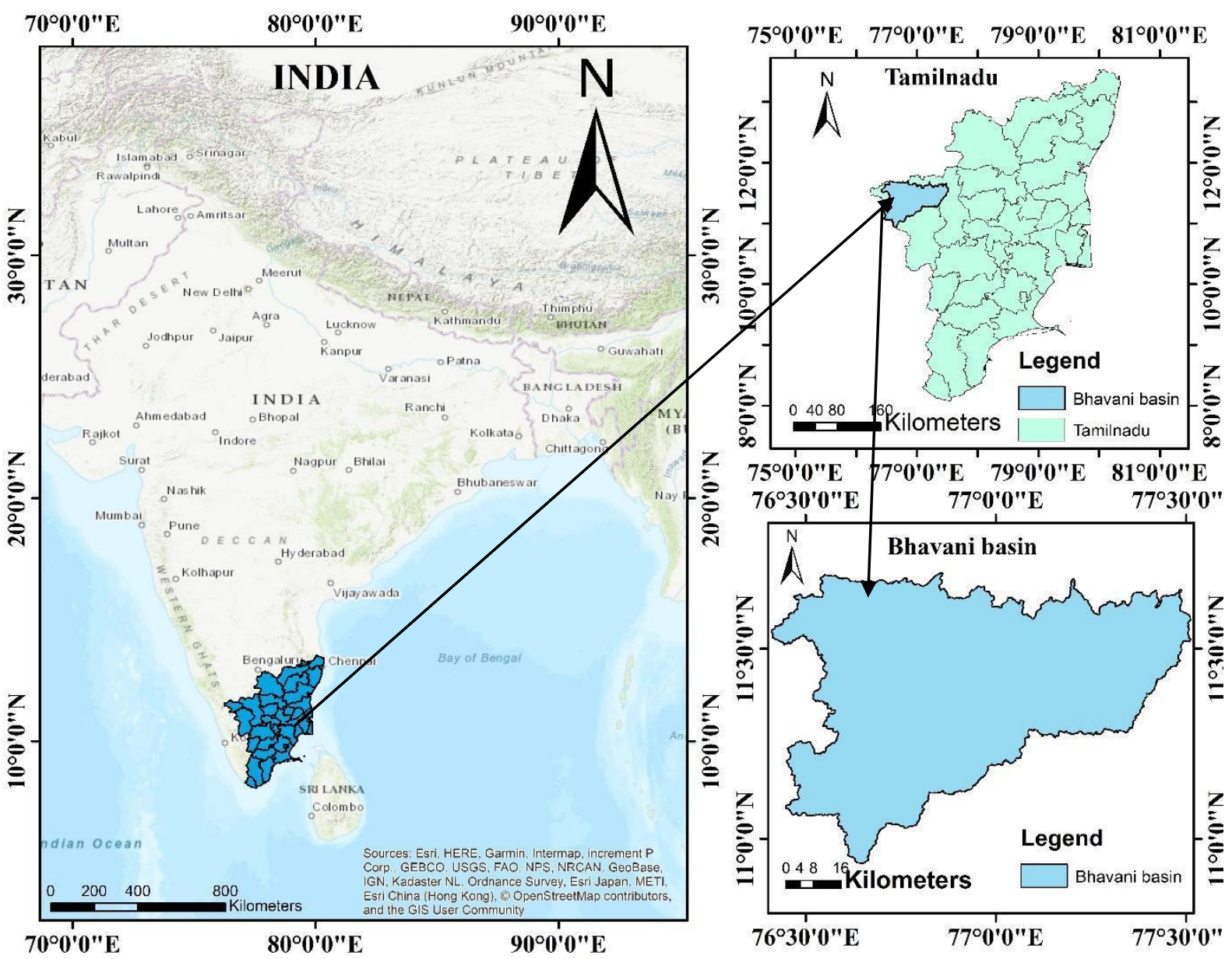

Fig:1 Bhavani Basin Study Area

MATERIALS AND METHOD

\section{Data collection}

The ground truth data was obtained during the dry season of March and was used for image classification and overall accuracy evaluation. Images from the Landsat satellite (with path/1999, 2007, 2014, and 2020 (row168/060) for four epochs multispectral data were collected from the Landsat TM satellite. The Table 1 gives the detailed description of the various parameters of the satellite data obtained for the analysis. 
Table 1: Source of Satellite Data

\begin{tabular}{|c|c|c|c|c|c|c|c|}
\hline Year & $\begin{array}{c}\text { Date- } \\
\text { Month }\end{array}$ & Path/Row & Satellite & Sensor & $\begin{array}{c}\text { Spatial } \\
\text { Resolution }\end{array}$ & $\begin{array}{c}\text { Origina } \\
\text { 1 Bands }\end{array}$ & Data Source \\
\hline 1999 & $28 / 03 / 1999$ & $144 / 52$ & LANDSAT 5 & TM & $30 \mathrm{~m}$ & $2,3,4,5$ & \\
\hline 2007 & $15 / 03 / 2007$ & $144 / 52$ & LANDSAT 5 & TM & $30 \mathrm{~m}$ & $\begin{array}{c}1,2,3,4, \\
5,6,7\end{array}$ & USGS \\
\hline 2014 & $12 / 03 / 2014$ & $144 / 52$ & LANDSAT 8 & $\begin{array}{c}\text { OLI/TI } \\
\text { RS }\end{array}$ & $30 \mathrm{~m}$ & $\begin{array}{c}1,2,3,4, \\
5,6,7,9\end{array}$ & USG \\
\hline 2020 & $22 / 03 / 2020$ & $144 / 52$ & LANDSAT 8 & $\begin{array}{c}\text { OLI/TI } \\
\text { RS }\end{array}$ & $30 \mathrm{~m}$ & $\begin{array}{c}1,2,3,4, \\
5,6,7,9\end{array}$ & \\
\hline
\end{tabular}

\section{METHODOLOGY}

This study involved the following main components for deriving the output: satellite acquisition, ancillary data acquisition, pre-processing, image classification, ground-truthing, and accuracy assessment. The Bhavani basin drainage network was clipped from the digital elevation model (DEM) using ARC GIS.The Landsat images UTM 43N were downloaded in Geotiff format from the USGS website. ERDAS imagine version 2015 software is required to convert the Geotiff to image format for image processing. This study area has covered a single path/row of the satellite image, so no need for mosaic work. The image enhancement is used for image visual interpretability and increasing the various feature distinctions. The enhanced imaginary processes attempted to visualise interpreting and optimise the human mind's complementary abilities and the computer (Shalaby \& Tateishi, 2007). The human can efficiently be interpreting the spatial attributes of an image and identify the subtle features. The LULC can be increased on the interpretation using different band combinations of Landsat images. The solid colour composite, false-colour composite, and natural colour composite following three composite colours are used in this study. The land cover classes are classified using digitised remote sensing data through image classification processes (Ismail, 2009).

This study used supervised classification for 1999, 2007, 2014, and 2020. The supervised classification was done using the Maximum likelihood classifier, while the supervised classification was the ISODATA technique (Iterative Self-organizing Data Analysis) (Foody, 2002). Without the need for user interaction, the algorithm evaluated all of the image's bands and identified clusters of pixels with similar values (Ismail, 2009). At the user's discretion, the sets were then allocated to their grades. These methods were supplemented with groundtruthing, Google Earth, and a topographical map to assign clusters to their groups. Simple random sampling was used for ground verification. The error/confusion matrix is used for validation; it is used to collect the information about actual and predicted image LULC classes done by classification processes (Foody, 2002).

\section{Land use and land cover classification}

The raw data must be correctly pre-processed and prepared to account for errors caused by the earth's geometry, radiometric effects, and atmospheric effects to perform image classification (J. S. Alawamy et al., 2020). The pre-processing stage included detecting and restoration of foul lines, geometric rectification or image registration, radiometric calibration, 
atmospheric correction, and topographic correction (MohanRajan et al., 2020; Tewabe \& Fentahun, 2020).

\section{Supervised image classification}

Pixels are chosen to reflect patterns that we recognise or can recognise with the aid of other sources of knowledge (Google Earth). The data and the groups are defined in detail. Before we could start choosing training samples, we need to know what algorithms we'd be using. By assigning preferences to these classes, the pixels are classified as they were assigned to a class attribute (Aneesha Satya et al., 2020).

\section{Accuracy assessment}

Kappa Coefficient must be compared to assumed-true reference data to evaluate and measure a classified image (MohanRajan et al., 2020). The technique was used to estimate image classification accuracy by comparing the LULC map to a LULC reference map (Aneesha Satya et al., 2020). As a result, a thorough accuracy assessment must include a report on overall precision, consumer accuracy, and producer accuracy, all of which were examined using the Kappa coefficient (Buğday \& Erkan Buğday, 2019).

\section{Image processing}

Incorrect line detection and restoration, geometric rectification, radiometric calibration, atmospheric correction, and topographic corrections are necessary for the pre-processing stage (Khan \& Jhariya, 2016). A classification method involving multiple sources of data necessitates precise geometric rectification (Tewabe \& Fentahun, 2020). The research used Landsat imagery to monitor LULC distribution changes in the basin over 20 years, from 1999 to 2020. To reduce seasonal variance and decrease cloud cover, the data collection dates were chosen during the dry season and with the same annual season as the established years. The (RGB) Red,Green,Blue, colour composition based on Landsat was used to create all of the raster images. Furthermore, the raster data covered the entire study area; band stacking and image sub-setting were all done with Erdas 2015 software (M. Chowdhury et al., 2018).

\section{RESULTS AND DISCUSSION}

\section{Kappa coefficient (KC)}

To see how well two sets of LULC map dataset is agreed, the Kappa statistic was used [20]

Table 2: Rate of Kappa Coefficient

\begin{tabular}{|c|c|c|}
\hline Categories & Kappa coefficient & Rate \\
\hline 1 & $<0.4$ & Poor \\
\hline 2 & $0.4-0.5$ & Fair \\
\hline 3 & $0.55-0.7$ & Good \\
\hline 4 & $0.7-0.85$ & Very good \\
\hline 5 & KC greater than 0.85 & Excellent \\
\hline
\end{tabular}




\section{Accuracy assessment}

Comparing classification to ground-truth data to see how well it fits the real world is known as accuracy assessment (A. Butt et al., 2015). In this study, 320 ground control points were used to check the classified images for the years 1999, 2007, 2014, and 2020, with the GPS point from Google Earth on the field being used in addition to the years' unchanged ground control point. Table 3 provides the produces and reference accuracy.

Table 3. Producer and Reference accuracy

\begin{tabular}{|c|c|c|c|c|}
\hline Year & $\begin{array}{c}\text { Producer } \\
\text { Datapoints }\end{array}$ & $\begin{array}{c}\text { Reference } \\
\text { Datapoints }\end{array}$ & $\begin{array}{c}\text { Overall } \\
\text { Accuracy } \\
\%\end{array}$ & $\begin{array}{c}\text { Kappa } \\
\text { Coefficient }\end{array}$ \\
\hline 1999 & 80 & 71 & 83.23 & 0.79 \\
\hline 2007 & 80 & 67 & 85.83 & 0.81 \\
\hline 2014 & 80 & 70 & 86.45 & 0.82 \\
\hline 2020 & 80 & 65 & 88.75 & 0.85 \\
\hline
\end{tabular}

An error matrix was used to conduct this analysis. The classification accuracy level was measured using Kappa statistics, and the total accuracy of the classified images from the ERDAS imagine version 2015 study section (Reddy et al., 2019). In 1999, 2007, 2014, and 2020 , the Kappa values were $0.79,0.81,0.82$, and 0.85 respectively. As a result, according to (Hadi, Shafri, and Mahir 2014) classification scale, the classification is in an excellent range.

\section{Land use/land cover classification, 1999-2020}

The four classified LULC prepared for the Bhavani Basin are presented in Table 3 and Figure: 1 The vegetation area was the most extensive land use/land cover in the Bhavani basin in the base year.

\section{Land use and land cover maps}

The generated false-color composite images are classified into water bodies, builtup land, barren land, and vegetation. Ground truth testing is also carried out to validate these findings, and classification is determined. Figures 2, 3, 4, and 5 display the LULC images obtained from Landsat images for 1999, 2007, 2014, and 2020. 


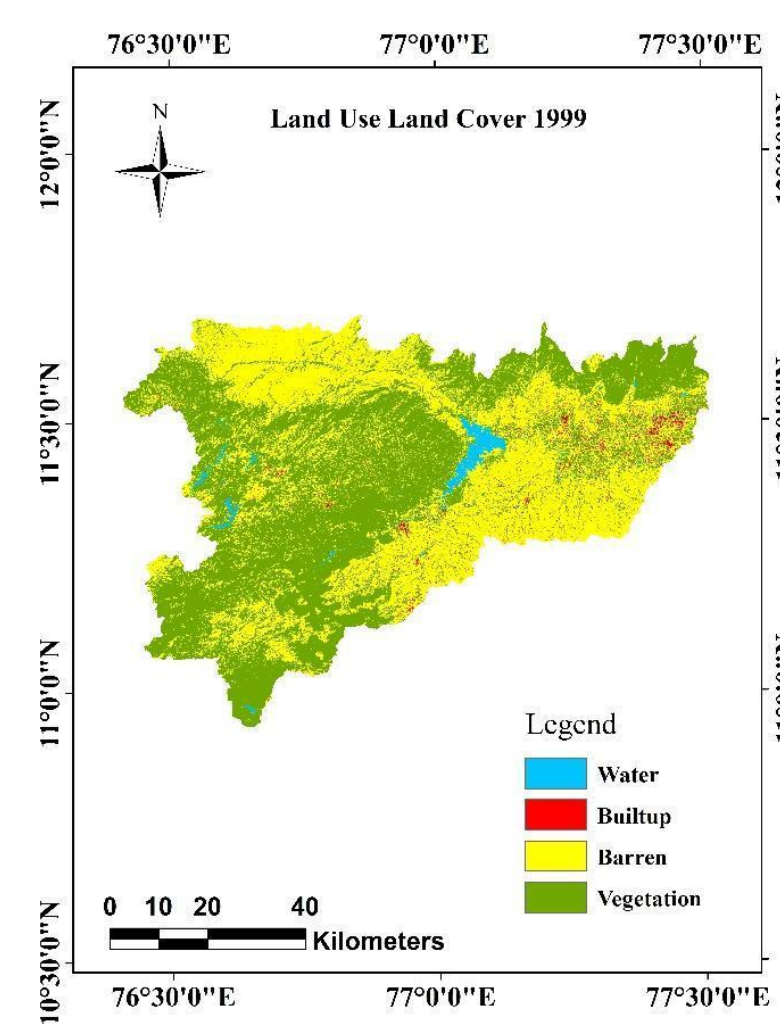

Fig :2 LULC map 1999

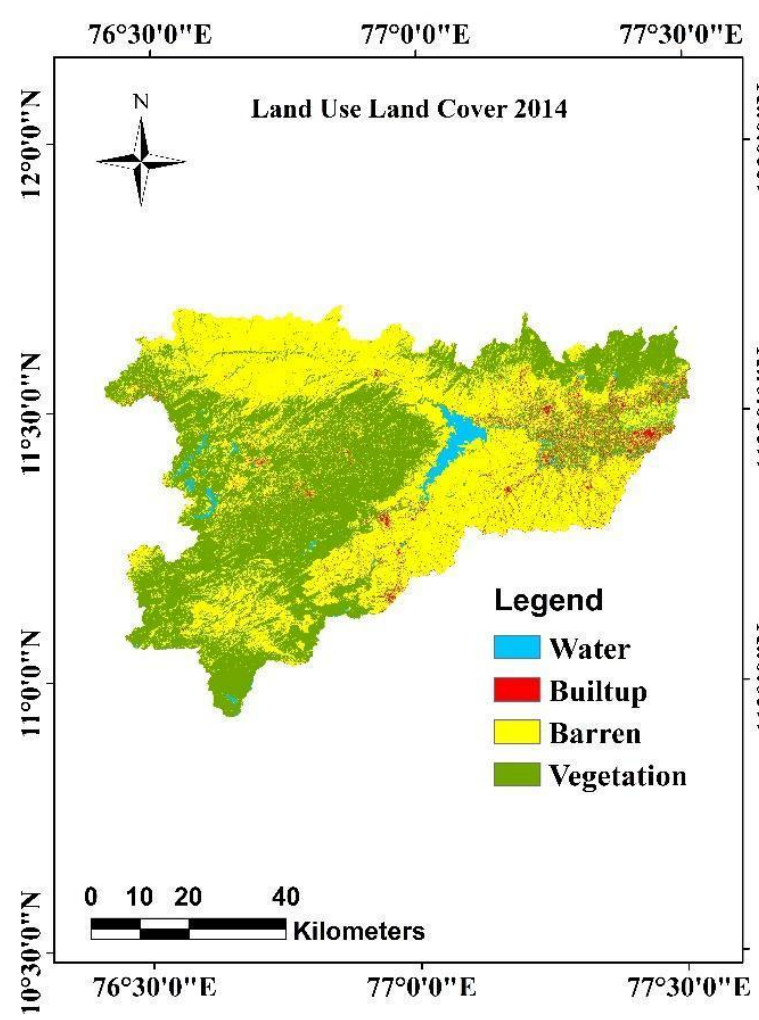

Fig :4 LULC map 2014

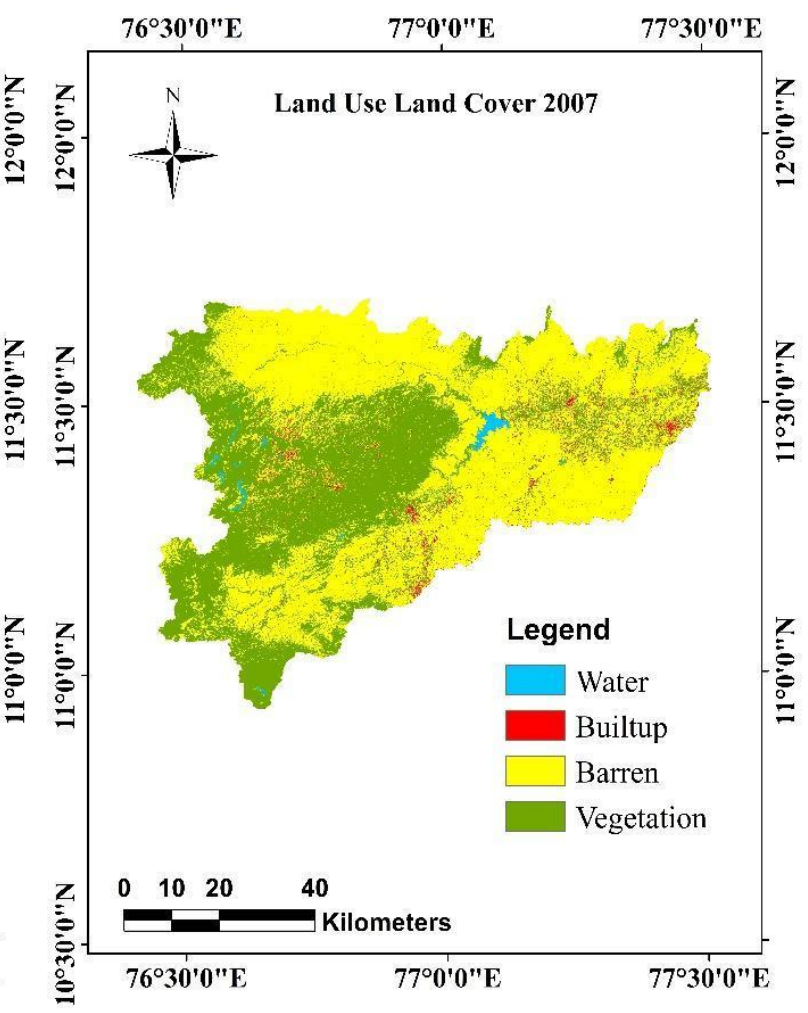

Fig :3 LULC map 2007

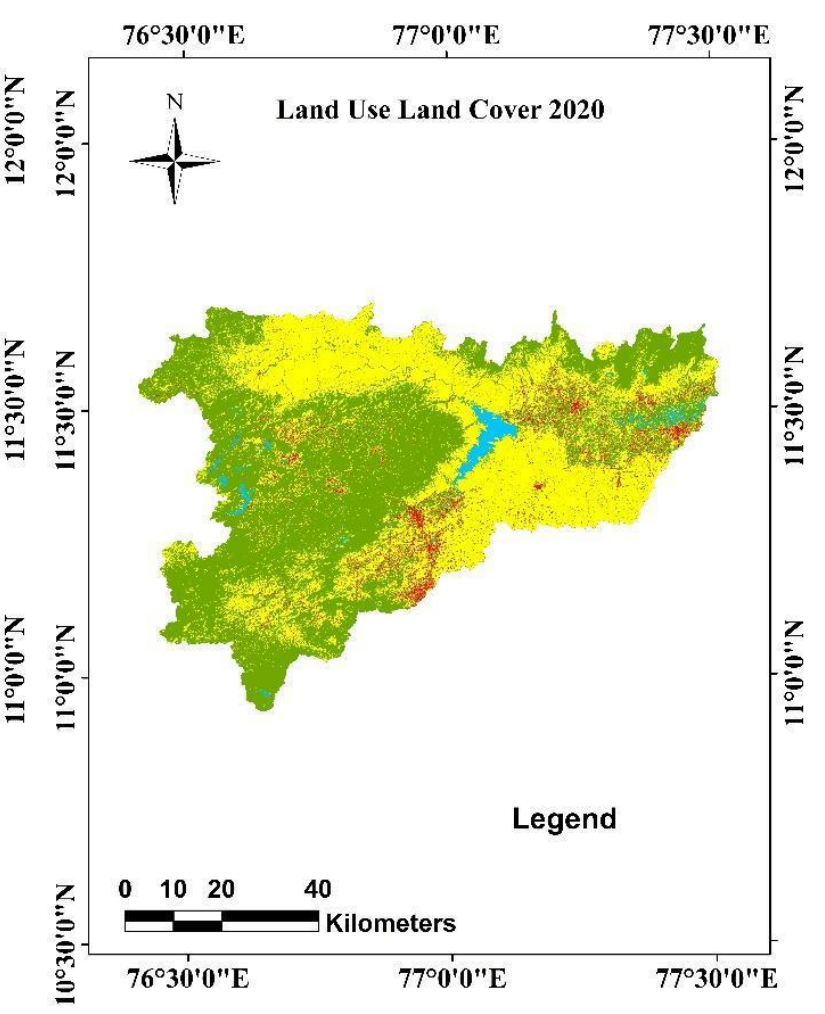

Fig :5 LULC map 2020 
Table 4 Land use/land cover classification of Bhavani, 1999-2020

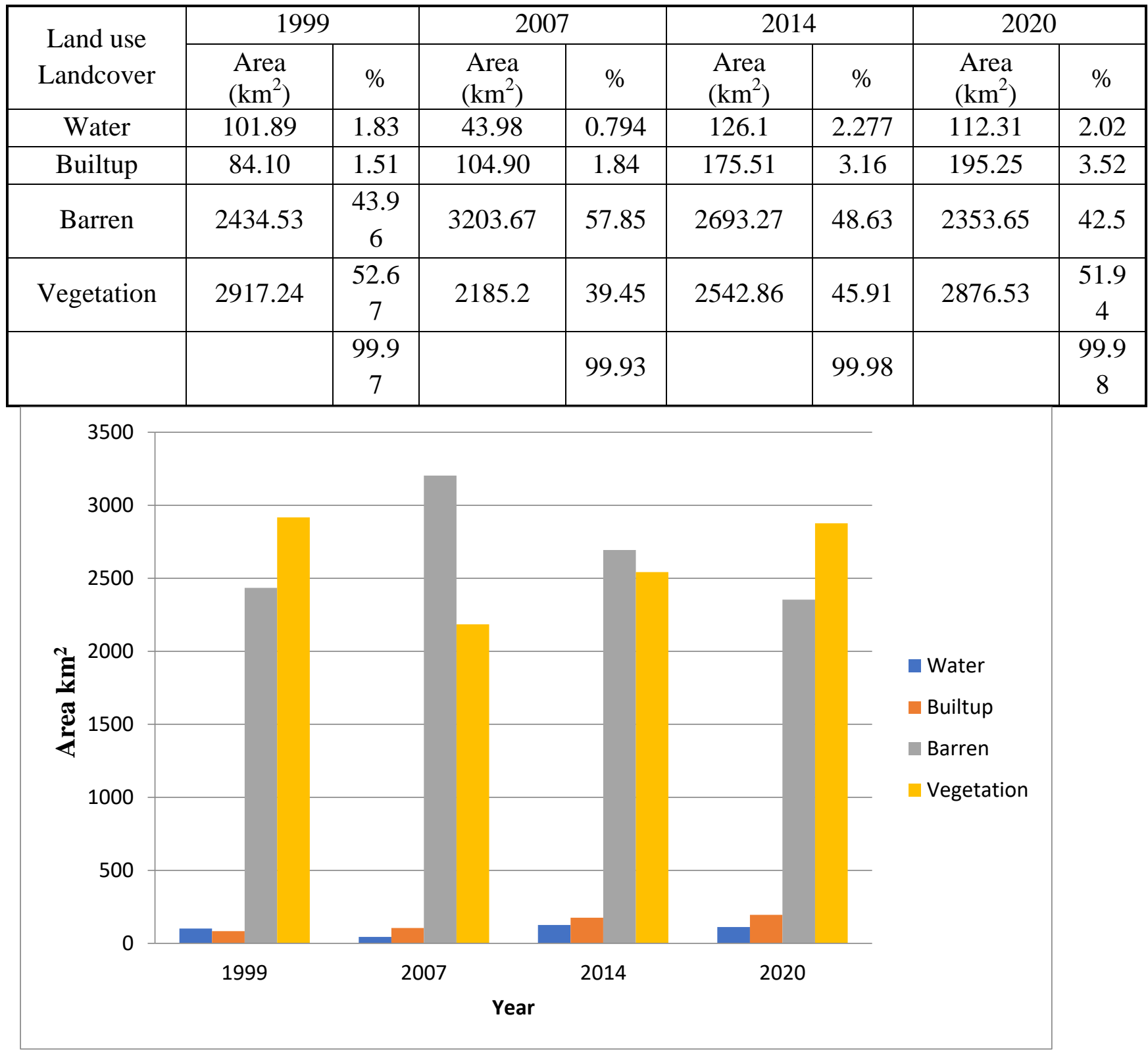

Fig:6 Land use/Land cover analysis 1999-2020

From the analysis it was found that the vegetation occupies $52.67 \%$ of the total drainage basin area in 1999, followed by water, builtup, barren occupying $1.83 \%, 1.51 \%$, and $43.96 \%$ of the total drainage area, respectively (Table 4 and Fig 6). In 2007, water, builtup, barren and vegetation covered $0.794 \%, 1.84 \%, 57.85 \%$, and $39.45 \%$ respectively of the total Bhavani basin area. Also, water, barren, and vegetation $2.277 \%, 48.63 \%$, and $45.91 \%$, respectively, while the built-up area accounted for $3.16 \%$ of the Bhavani basin area in 2014 . Water and barren accounted for $2.02 \%$ and $42.5 \%$, and while the built-up area and vegetation area accounted for $3.52 \%$ and $51.94 \%$ of the Bhavani basin area in 2020. The Kappa coefficient and overall accuracy for the LULC map of 1999 were 0.83 and 0.79 , respectively. The kappa coefficient and overall accuracy were 0.85 and 0.81 for the year 2007 LULC map. For the LULC map of 2014, the kappa coefficient and overall accuracy were both 0.86 and 
0.82 , respectively. The kappa coefficient and overall accuracy were found to be 0.88 and 0.85 , respectively, for the LULC map of 2020.

\section{Land use/land cover change analysis, 1999-2020}

The findings are described in the following tables, and a shift detection matrix was developed to explain the changes in one LULC class to another during the study period.

Table 5 Land use/land cover categories in Bhavani Basin, 1999-2007.

\begin{tabular}{|l|c|c|c|c|c|c|}
\hline \multicolumn{1}{|c|}{ Class } & 1999 & 2007 & $\begin{array}{c}\text { Change } \\
\text { Area } \\
\left(\mathrm{km}^{2}\right)\end{array}$ & $\begin{array}{c}1999 \\
(\%)\end{array}$ & $\begin{array}{c}2007 \\
(\%)\end{array}$ & $\begin{array}{c}\text { Change } \\
(\%)\end{array}$ \\
\hline Water & 101.89 & 43.98 & -57.91 & 1.83 & 0.794 & -1.04 \\
\hline Builtup & 84.10 & 104.90 & 20.80 & 1.51 & 1.84 & 0.375 \\
\hline Barren & 2434.53 & 3203.67 & 769.14 & 43.96 & 57.85 & 13.88 \\
\hline Vegetation & 2917.24 & 2185.2 & -732.04 & 52.67 & 39.45 & -13.21 \\
\hline
\end{tabular}

Between 1999-2007 the water body area decreased by $1.04 \%$ in 1999 compared with the water body in 2007 . The barren land got increased, and vegetation was reduced by $13.88 \%$ and $13.21 \%$, respectively. This is due to the decrease in rainfall during the year 2007 by 117 $\mathrm{mm}$ which is insufficient to fill the water bodies. This also increased the barren significantly from the agricultural land (Table 5).

Table 6 Land use/land cover categories in Bhavani basin, 2007-2014.

\begin{tabular}{|l|c|c|c|c|c|c|}
\hline \multicolumn{1}{|c|}{ Class } & 2007 & 2014 & $\begin{array}{c}\text { Change } \\
\text { Area } \\
\left(\mathrm{km}^{2}\right)\end{array}$ & $\begin{array}{c}2007 \\
(\%)\end{array}$ & $\begin{array}{c}2014 \\
(\%)\end{array}$ & $\begin{array}{c}\text { Change } \\
(\%)\end{array}$ \\
\hline Water & 43.98 & 126.10 & 82.12 & 0.79 & 2.20 & 1.48 \\
\hline Builtup & 104.9 & 175.51 & 70.61 & 1.89 & 3.16 & 1.25 \\
\hline Barren & 3203.67 & 2693.27 & -510.4 & 57.95 & 48.63 & -9.21 \\
\hline Vegetation & 2185.20 & 2542.86 & 357.67 & 39.45 & 45.91 & 6.45 \\
\hline
\end{tabular}

Between 2007-2014 the water body area got increased by $1.48 \%$ in the year 2014 compared with the water body in 2007. The barren land was decreased, and vegetation got increased in the year 2014 with $-9.21 \%$ and $6.45 \%$, respectively. In 2014 , the annual rainfall is increased compared to 2007 annual rainfall led to sufficient rain to fill up the water bodies and automatically increased the vegetation area. Due to the increase in the rainfall, the agricultural land has been increased significantly from barren land (Table 6). 
Table 7 Land use/land cover categories in Bhavani Basin 2014-2020

\begin{tabular}{|l|c|c|c|c|c|c|}
\hline Class & 2014 & 2020 & $\begin{array}{c}\text { Change } \\
\text { Area } \\
\left(\mathrm{km}^{2}\right)\end{array}$ & $2014(\%)$ & $2020(\%)$ & $\begin{array}{c}\text { Change } \\
(\%)\end{array}$ \\
\hline Water & 126.1 & 112.31 & -1379 & 2.277 & 2.02 & -0.24 \\
\hline Builtup & 175.51 & 195.25 & 19.74 & 3.16 & 3.52 & 0.35 \\
\hline Barren & 2693.27 & 2353.65 & -339.62 & 48.63 & 42.5 & -6.13 \\
\hline Vegetation & 2542.86 & 2876.53 & 333.67 & 45.91 & 51.94 & 6.02 \\
\hline
\end{tabular}

Between 2014-2020 the water body area decreased by -0.24\% when compared between 2014 and 2020. The barren land was reduced, and vegetation got increased with -6.13 and $6.02 \%$ respectively. The improper maintenance of water bodies and the silting of tributaries contributing water to the main canal leads to the decrease in waterbody area, but with modern irrigation techniques and other command management measures the vegetation area got increased by $6.02 \%$ in the year 2020 .

\section{CONCLUSION}

LULC changes are influenced by a variety of geological, environmental, and socioeconomic factors. Authorities effectively use remote sensing and GIS-based LULC studies for resource management. The survey of LULC in the Bhavani basin over the last 20 years was investigated and the findings revealed that significant changes were detected during the study period. Primary land use in the basin area is vegetation (50\%), barren land (40\%) and the remaining $10 \%$ is covered by water bodies and builtup land. This study shows that the builtup land area had increased from $84.1 \mathrm{~km}^{2}$ in 1999 to $195.25 \mathrm{~km}^{2}$ in 2020 . From 1999 to 2020, the maximum vegetation and barren was found to be $2917 \mathrm{~km}^{2}$ and $3203 \mathrm{~km}^{2}$ in the year 1999 and the minimum vegetation $\left(2185 \mathrm{~km}^{2}\right)$ and barren $\left(2434 \mathrm{~km}^{2}\right)$ was found to be in the 2007 and 2020. Increase in the vegetation area and reduction in the barren area ultimately results in low soil erosion. Also, practising soil erosion preventive measures such as check dams, gabions decrease soil erosion in the basin. 


\section{REFERENCES}

J. S. Alawamy, S. K. Balasundram, A. H. M. Hanif, and C. T. B. Sung, 2020“Detecting and analyzing land use and land cover changes in the Region of Al-Jabal Al-Akhdar, Libya using time-series landsat data from 1985 to 2017," Sustainability (Switzerland), vol. 12, no. 11, 2020, doi: 10.3390/su12114490.

M. H. Saputra and H. S. Lee, 2019 "Prediction of land use and land cover changes for North Sumatra, Indonesia, using an artificial-neural-network-based cellular automaton," Sustainability (Switzerland), vol. 11, no. 11, Jun. 2019, doi: 10.3390/su11113024.

U. Imran Basha, U. Suresh, G. Sudarsana Raju, M. Rajasekhar, G. Veeraswamy, and E. Balaji, 2018 "Landuse and landcover analysis using remote sensing and GIS: A case study in somavathi river, Anantapur district, Andhra Pradesh, India," Nature Environment and Pollution Technology, vol. 17, no. 3, pp. 1029-1033.

S. Twisa and M. F. Buchroithner, 2019 "Land-use and land-cover (LULC) change detection in Wami river basin, Tanzania," Land, vol. 8, no. 9, doi: 10.3390/land8090136.

E. D. Ashaolu, J. F. Olorunfemi, and I. P. Ifabiyi, 2019“Assessing the Spatio-Temporal Pattern of Land Use and Land Cover Changes in Osun Drainage Basin, Nigeria," Journal of Environmental Geography, vol. 12, no. 1-2, pp. 41-50, May , doi: 10.2478/jengeo-20190005 .

B. Ebenezer, K. A. Geophery, A. Q.-B. Jonathan, and A. D. Emmanuel, 2018 "Land use change and sediment yield studies in Ghana: Review," Journal of Geography and Regional Planning, vol. 11, no. 9, pp. 122-133, Sep, doi: 10.5897/jgrp2018.0707.

A. Butt, R. Shabbir, S. S. Ahmad, and N. Aziz, 2015 "Land use change mapping and analysis using Remote Sensing and GIS: A case study of Simly watershed, Islamabad, Pakistan,” Egyptian Journal of Remote Sensing and Space Science, vol. 18, no. 2, pp. 251259, doi: 10.1016/j.ejrs.2015.07.003.

M. Chowdhury, M. E. Hasan, and M. M. Abdullah-Al-Mamun, 2020 "Land use/land cover change assessment of Halda watershed using remote sensing and GIS," Egyptian Journal of Remote Sensing and Space Science, vol. 23, no. 1, pp. 63-75, doi: 10.1016/j.ejrs.2018.11.003.

S. Das and R. Sarkar, 2019 "Predicting the land use and land cover change using Markov model: A catchment level analysis of the Bhagirathi-Hugli River," Spatial Information Research, vol. 27, no. 4, pp. 439-452, 2019, doi: 10.1007/s41324-019-00251-7.

M. L. G. Guidigan, C. L. Sanou, D. S. Ragatoa, C. O. Fafa, and V. N. Mishra, 2019 “Assessing Land Use/Land Cover Dynamic and Its Impact in Benin Republic Using Land 
Change Model and CCI-LC Products," Earth Systems and Environment, vol. 3, no. 1, pp. 127-137, doi: 10.1007/s41748-018-0083-5.

P. Mzava, J. Nobert, and P. Valimba, 2019 "Land Cover Change Detection in the Urban Catchments of Dar es Salaam, Tanzania using Remote Sensing and GIS Techniques," Tanzania Journal of Science, vol. 45, no. 3, pp. 315-329, [Online]. Available: www.ajol.info/index.php/tjs/.

N. Alam, S. Saha, S. Gupta, and S. Chakraborty, 2021 "Prediction modelling of riverine landscape dynamics in the context of sustainable management of floodplain: a Geospatial approach," Annals of GIS, doi: 10.1080/19475683.2020.1870558.

Zahra Hassan, Rabia Shabbir, Sheikh Saeed Ahmad, Amir Haider Malik, Neelam Aziz, Amna Butt \& Summra Erum,2016 "Dynamics of land use and land cover change (LULCC) using geospatial techniques: a case study of Islamabad Pakistan," SpringerPlus, vol. 5, no. 1, 2016, doi: 10.1186/s40064-016-2414-z.

M. H. Elagouz, S. M. Abou-Shleel, A. A. Belal, and M. A. O. El-Mohandes, 2020 "Detection of land use/cover change in Egyptian Nile Delta using remote sensing," Egyptian Journal of Remote Sensing and Space Science, vol. 23, no. 1, pp. 57-62, doi: 10.1016/j.ejrs.2018.10.004.

V. Narayanamurthi, 2020 "Impact of climate change in sediment yield from catchment of bhavanisagar reservoir using SWAT model," no. January.

Ministry of India water resources, 2017 "Central Ground Water Board Ministry of Water Resources, River Development and Ganga Rejuvenation Government of India ..AQUIFER MAPPING AND GROUND WATER ".

A. Shalaby and R. Tateishi, 2007 "Remote sensing and GIS for mapping and monitoring land cover and land-use changes in the Northwestern coastal zone of Egypt," Applied Geography, vol. 27, no. 1, pp. 28-41, 2007, doi: 10.1016/j.apgeog.2006.09.004.

M. H. Ismail, 2009 "Evaluating supervised and unsupervised techniques for land cover mapping using remote sensing data," Geografia: Malaysian Journal of Society and Space, vol. 5, no. 1, pp. 1-10.

G. M. Foody, 2002 "Status of land cover classification accuracy assessment," Remote Sensing of Environment, vol. 80, no. 1, pp. 185-201, 2002, doi: 10.1016/S00344257(01)00295-4. 
D. Tewabe and T. Fentahun, 2020 "Assessing land use and land cover change detection using remote sensing in the Lake Tana Basin, Northwest Ethiopia," Cogent Environmental Science, vol. 6, no. 1, doi: 10.1080/23311843.2020.1778998.

S. N. MohanRajan, A. Loganathan, and P. Manoharan, 2020 "Survey on Land Use/Land Cover (LU/LC) change analysis in remote sensing and GIS environment: Techniques and Challenges," Environmental Science and Pollution Research, vol. 27, no. 24. pp. 2990029926, doi: 10.1007/s11356-020-09091-7.

B. Aneesha Satya, M. Shashi, and P. Deva, 2020 "Future land use land cover scenario simulation using open source GIS for the city of Warangal, Telangana, India," Applied Geomatics, vol. 12, no. 3, pp. 281-290, doi: 10.1007/s12518-020-00298-4.

E. Buğday and S. Erkan Buğday, 2019 "Modeling and simulating land use/cover change using artificial neural network from remotely sensing data," Cerne, vol. 25, no. 2, pp. 246254, Apr, doi: 10.1590/01047760201925022634.

R. Khan and D. C. Jhariya, 2016 "Land Use Land Cover Change Detection Using Remote Sensing and Geographic Information System in Raipur Municipal Corporation Area, Chhattisgarh," Scientific Society of Advanced Research and Social Change SSARSC International Journal of Geo Science and Geo Informatics, vol. 3, no. 1, pp. 2348-6198, [Online]. Available: www.ssarsc.org.

K. R. Reddy, S. Devaraj, S. Biradar, K. Yarrakula, and K. Srinivas Kumar, 2019 "Spatial distribution of land use/ land cover analysis in Hanamkonda taluk, Telangana - A case study," Indian Journal of Geo-Marine Sciences, vol. 48, no. 11, pp. 1761-1768, 2019. 